\title{
Assessment of Risk Factors for Cardiovascular Complications in Patients with Chronic Kidney Disease (CKD) Stage III- V before Dialysis
}

\author{
KHAN MK ${ }^{1}$, RASHID HU ${ }^{2}$, YESMINE $S^{3}$, MAHMOO IH ${ }^{1}$, HABIB SMA ${ }^{4}$, HOSSAIN A ${ }^{5}$ \\ ${ }^{1}$ Department of Nephrology, Bangladesh Medical College Hospital, Dhaka, ${ }^{2}$ Department of Nephrology, Bangabandhu Sheikh \\ Mujib Medical University, Dhaka, ${ }^{3}$ Department of Pharmacy, Jahangir Nagar University, Savar, Dhaka, ${ }^{4}$ Department of \\ Cardiology Bangabandhu Sheikh Mujib Medical University, Dhaka, ${ }^{5}$ Department of Cardiology, Bangladesh Medical College \\ Hospital, Dhaka \\ Address of Correspondence: Dr. Masum Kamal Khan, Department of Nephrology, \\ Bangladesh Medical College Hospital, Dhaka.
}

\begin{abstract}
:
Background. Chronic Kidney Disease is a major public health and clinical problem throughout the world including Bangladesh. The prevalence of cardiovascular complications is much higher in patients with CKD regardless of stages than normal population. Considering this view, a cross sectional study was conducted in the Department of Nephrology, Bangabandhu Sheikh Mujib Medical University (BSMMU), Dhaka, with an aim to assessing the cardiovascular complications \& associated risk factors among the patients with chronic kidney disease (CKD) stage III-V before dialysis.

Methods. A total of 109 patients were selected consecutively who had a diagnosis of CKD and an estimated GFR of less than $60 \mathrm{ml} / \mathrm{min} / 1.73 \mathrm{~m}^{2}$ of stages III to $\mathrm{V}$ and who had not received any form of renal replacement therapy, during a period of June 2006 to July 2007.

Results.The study included 63 males and 46 females with age ranging from 18 to 65 years having a mean age 45.5 \pm 12.2 years. Left ventricular failure, left ventricular hypertrophy (by ECG and echocardiography), cardiomegally by $X$-ray were identified as significant cardiovascular complications among the patients of $C K D$ stage $V(p<0.05)$. However, logistic regression analysis revealed that hypertension and CKD stages appeared to be the important predictors of cardiovascular complications $p<0.05$ ). Data analysis found that hypertension, smoking and anemia appeared to be important risk factors for cardiovascular complications in CKD patients $(\boldsymbol{p}<0.05)$ by bi-variate analysis.

Conclusion. Though the study findings did not generalize the CKD patients in Bangladesh due to small sample size, however, heart failure and left ventricular hypertrophy significantly appeared to be the main cardiovascular complications in CKD stage V compared to other two stages (stage III and IV) $(p<0.05)$. Anemia, hypertension were identified as important risk factors $(p<0.05)$.
\end{abstract}

Introduction:

Chronic kidney disease is defined as structural or functional abnormalities of kidneys with or without reduction of glomerular filtration rate persisting for three months or above, manifested by either pathological or kidney function abnormality markers observed in urine, blood or imaging. ${ }^{1}$

Cardiovascular disease (CVD) is common in patients with chronic kidney disease regardless of the stage of renal impairment. ${ }^{2,3}$ Whether the patients have moderately reduced kidney function, are undergoing dialysis, or have received a transplant, the prevalence and incidence of CVD are much higher in this group than in a sex- and agematched control population. Cardiovascular disease (CVD) is the leading cause of death in patients with
Chronic Kidney Disease (CKD) regardless of stages ${ }^{4}$. Cardiovascular disease (CVD) is the most common cause of death in patients who have end-stage renal disease and is 10 to 100 times more common in patients with kidney disease than in those of the same age and sex without kidney disease. Forty percent to $50 \%$ of all deaths in EndStage Renal Disease (ESRD) patients are of cardiovascular origin. ${ }^{5}$ Cardiovascular causes also account for the majority of deaths among patients with predialysis kidney disease. ${ }^{1,6}$ A Canadian cohort study showed that $40 \%$ of patients starting dialysis already had evidence of Coronary Heart Disease (CHD), and only 16\% had normal echocardiographic studies. ${ }^{7}$

Different studies in chronic kidney disease have shed light on the striking incidence of cardiovascular disease co- 
morbidity that is characteristic of all stages of this illness. ${ }^{8}$ The patients with CKD are faced with 3 distinct types of CVD, all of which are likely to lead to poor outcomes. ${ }^{9}$ These include left ventricular hypertrophy with both eccentric and concentric variants, atherosclerosis, and arteriosclerosis. Eccentric LVH is characterized by an increase in wall thickness that is in proportion to the increase in LV diameter and results from volume overload due to fluid retention, anaemia or an A-V fistula. Concentric LVH occurs when the thickness of the LV is greater than the changes in the LV diameter and is attributable to hypertension typical of CKD and related aortic vessel stiffening. Atherosclerosis is the key element to occlusive vascular disease and ischaemic heart disease. Atherosclerosis leads to luminal narrowing of both large and coronary arteries, both of which contribute to the increased incidence of myocardial infarction observed in this population.

Cardiovascular mortality, left ventricular hypertrophy, congestive heart failure, and new coronary events are excessive in patients with kidney disease, regardless of patient age. 2,10,11,12 In patients who have CKD but have not yet undergone dialysis, the prevalence of left ventricular hypertrophy increases with declining kidney function. As a consequence congestive heart failure and angina occur in conjunction with worsening hypertrophy. ${ }^{13}$

Hypertension is a common problem in CKD patients, and evidence strongly supports an association between hypertension and the occurrence of cardiovascular complications in this population. ${ }^{14,15}$ Identification and treatment of hypertension is important in CKD patients in order to slow the decline of renal function. As a matter of fact good blood pressure control will slow the progression of all types of kidney disease. The severity of CKD and resultant proteinuria confirms increased risk of CVD mortality. ${ }^{16,17,18}$ The blood pressure target in patients with CKD not undergoing dialysis is less than $130 / 80 \mathrm{~mm} \mathrm{Hg}^{19}$. In patients with proteinuria greater than $1 \mathrm{gm} / 24 \mathrm{hrs}$, blood pressure should be reduced to less than 125/75 mm Hg. ${ }^{19}$ This target level has been shown to reduce the rate of decline in kidney function and may also reduce cardiovascular complications. In stages 3 and 4 CKD (i.e. pre-ESRD), antihypertensive therapy improves left ventricular hypertrophy $(\mathrm{LVH}){ }^{20}$

A large proportion of patients with CKD have diabetes. Diabetes is a significant risk factor for cardiovascular disease, and this risk is even higher in diabetic patients with renal complications. Diabetes control has been shown to reduce macrovascular and microvascular disease, according to the findings of the Diabetes Control and Complications Trial ${ }^{21}$ and the United Kingdom Prospective Diabetes Study (UKPDS). ${ }^{22}$ Since almost $40 \%$ of patients starting dialysis have diabetes and the burden of illness is high in this group, blood glucose control is of paramount importance in reducing CVD risk in patients with CKD. It is reasonable to attempt to achieve tight glycemic control (i.e.glycosylated hemoglobin concentration of 7\%) in CKD patients with diabetes.

The prevalence of hyperlipidaemia is higher in patients with CKD than in general population but varies depending on the specific lipid measured, target population, course of renal disease, and level of renal function. Total and Low Density Lipoprotein (LDL) cholesterol levels are increased most often in patients with chronic renal insufficiency and nephrotic syndrome, in patients treated by peritoneal dialysis and in renal transplant recipients. ${ }^{23}$ Lipid-lowering agents are effective in reducing the elevated cholesterol and triglycerides levels often present in patients in kidney and heart disease. Study data support that dyslipidaemia is a contributing factor in kidney function decline, and some epidemiologic data suggest that dyslipidaemia may be a risk factor for kidney disease. ${ }^{24}$

Anaemia is associated with CVD in all patients with kidney disease. A growing body of evidence supports the role of anaemia as a correlate of left ventricular hypertrophy, and therefore, a cardiac risk factor in CKD patients beginning at the early stages of renal disease. ${ }^{25,13}$ One of the associations is that increase in left ventricular hypertrophy and congestive heart failure occur at lower levels of hemoglobin. ${ }^{26,27}$ In a Canadian cohort of predialysis patients with renal insufficiency, a $0.5 \mathrm{~g} / \mathrm{dL}$ decrease in hemoglobin level was associated with a $32 \%$ increase in the risk of left ventricular hypertrophy. ${ }^{13}$ Regression of left ventricular hypertrophy is achievable with correction of anaemia. Data published in 2000 suggest that treatment of anaemia may reduce hospitalizations caused by heart disease, especially congestive heart failure. ${ }^{28}$

Previous studies have demonstrated that smoking further aggravates the excessive cardiovascular risk in patients with impaired renal function. ${ }^{29}$ In a study, it has been found that ESRD patients in the United States, smokers had a 22\% greater risk of developing coronary artery disease. ${ }^{30}$

Early intervention is needed to minimize the burden of cardiovascular disease in CKD patients. Risk reduction strategies are likely to be effective in reducing cardiovascular morbidity and mortality in CKD patients in the same way as these interventions improve outcomes in the general population. 


\section{Risk Factors for Cardiovascular Disease in CKD}

Two types of risk factors have been defined in patients with CKD. ${ }^{9}$ Traditional risk factors, described primarily in the Framingham population include among others, hypertension, diabetes, hyperlipidaemia, smoking, male sex and LVH. Although the patients with CKD have high prevalence of many of these traditional risk factors, they are also exposed to non-traditional or uraemia related risk factors that increase in prevalence as kidney function declines.

Table-I

Risk factors for cardiovascular complications in patients with $C K D^{9}$

\begin{tabular}{ll}
\hline Traditional risk factors & $\begin{array}{l}\text { Non-traditional or uraemia } \\
\text { related risk factors }\end{array}$ \\
\hline Diabetes mellitus & Anaemia \\
Hypertension & Hyperhomocysteinaemia \\
Dyslipidaemia & Abnormal mineral metabolism \\
Smoking & Hyperparathyroidism \\
Physical inactivity & Oxidative stress \\
Advanced age & Malnutrition \\
Male Sex & Inflammation \\
Menopause & Thrombogenic factors \\
Family history of CVD & \\
LVH & \\
\hline
\end{tabular}

Both traditional and non-traditional risk factors are associated with CVD in CKD patients; diabetes, hypertension, age, gender and dyslipidaemia are known to contribute to atherosclerotic processes. Moreover, in CKD patients, non-traditional risk factors such as anaemia, abnormal mineral metabolism, hyperparathyroidsm, hyperhomocysteinaemia and increase in pro-inflammatory cytokines have been linked with CVD.

\section{Materials and Methods:}

Study setting

This was a cross-sectional study to find out the cardiovascular complications in patients with chronic kidney disease of stage III-V before dialysis conducted in the Department of Nephrology, Bangabandhu Sheikh Mujib Medical University (BSMMU), Dhaka from June 2006 to July 2007. All patients gave their informed written consent to participation. Study population were the patients of chronic kidney disease of stages III to $\mathrm{V}$ who were admitted to BSMMU in the Department of Nephrology, and had not received any form of renal replacement therapy. Included patients were between 18 and 65 years of age. Patients suffering from congenital or valvular heart disease and cirrhosis of liver were excluded from the study.

\section{Laboratory Tests}

- 5 cc of blood was collected from each patient and was sent for biochemical analysis

- Urine was collected in test tube and was also sent for analysis

In all patients, the following tests were performed:

- Urine for routine and microscopic examination

- Haemoglobin

- Blood urea \& S. Creatinine

- Blood Sugar- FBS or BS 2 hours after breakfast

- $\quad$ S. Lipid Profile- fasting

- X-ray chest P/A view

- Ultrasonography of Kidney, Ureter and Bladder (KUB)

- Standard 12-lead electrocardiography

- Echocardiogram (M-Mode 2-D)

Chronic Kidney Disease: The National Kidney Foundation (NKF) defines chronic kidney disease as a kidney damage or a glomerular filtration rate (GFR) of less than $60 \mathrm{ml}$ per minute per $1.73 \mathrm{~m}^{2}$ body surface area for three months or more [31]. The most commonly used formulas for estimating GFR in patients with stable chronic kidney disease are the Cockcroft-Gault Equation and the Modification of Diet in Renal Disease (MDRD) equation.

Equations for predicting GFR in patients with stable chronic kidney disease

COCKCROFT-GAULT EQUATION:

(140-age in years) $\mathrm{X}$ Wt in KG

$\mathrm{C}_{\mathrm{cr}}(\mathrm{ml}$ per minute $)=\frac{72 \mathrm{X} \mathrm{S}_{\mathrm{cr}} \text { in } \mathrm{mg}}{X}(0.85$ if female $)$

Abbreviated MDRD (Modification of Diet in Renal Disease) study equation:

GFR $\left(\mathrm{ml} / \mathrm{minute} / 1.73 \mathrm{~m}^{2}\right)=186 \mathrm{X}\left(\mathrm{S}_{\mathrm{cr}}\right)^{-1.154} \mathrm{X}(\text { Age })^{-0.203}$ $\mathrm{X}$ (0.742 if female) X (1.210 if black)

GFR = Glomerular Filtration rate, $\mathrm{MDRD}=$ Modification of Diet in Renal Disease. $\mathrm{S}_{\mathrm{cr}}=$ Serum creatinine concentration. $\mathrm{C}_{\mathrm{cr}}=$ creatinine clearance $^{32,33,34}$.

The NKF Kidney Disease Outcome Quality Initiative (K/ DOQI) stratifies chronic kidney disease into five stages based on the GFR and metabolic consequences. 
Table-II

Stages of Chronic Kidney Disease (NKF 2002)

\begin{tabular}{lcc}
\hline Stage description & GFR $\left(\mathrm{ml} /\right.$ minutes $/ 1.73 \mathrm{~m}^{2}$ & Metabolic consequences \\
\hline $\begin{array}{l}\text { 1. Kidney damage (early) } \\
\text { with normal or elevated }\end{array}$ & 90 or higher \\
GFR
\end{tabular}

2. Kidney damage with mildly decreased GFR (early renal insufficiency)

3. Moderately decreased GFR (Moderate kidney failure)

4. Severely decreased GFR (pre-endstage kidney disease)
60-89

5. Kidney failure (end-stage kidney disease) $<15$ (or dialysis)

Parathyroid hormone begins to rise (GFR 60-80)

Calcium absorption decreases (GFR below 50). There is onset of left ventricular hypertrophy and/or anaemia (erythroproietin deficiency) Lipoprotein activity declines Malnutrition develops

Triglyceride concentration begins to rise.

Hyperphosphataemia or metabolic acidosis develops

\section{Results:}

This was a cross sectional study conducted in the Department of Nephrology, Bangabandhu Sheikh Mujib Medical University (BSMMU), Dhaka. A total of 109 patients were studied with a view to assessing the cardiovascular complications among the patients with chronic kidney disease (CKD) in stage III-V before dialysis.

Based on Estimated Glomerular Filtration Rate (eGFR) all the patients weredivided into three groups such as Stage

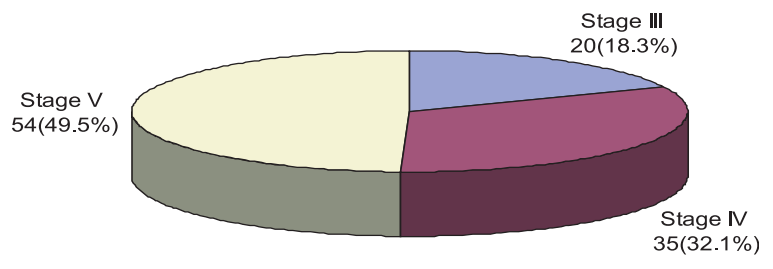

Fig.-1: Percentage distribution of stages of CKD $(n=109)$
III: 30-59 ml/min, Stage IV: $15-29 \mathrm{ml} / \mathrm{min}$ and Stage V: $<15 \mathrm{ml} / \mathrm{min}$

Baseline demographic characteristics of the patients are shown in Table 3

The mean age of the stage III, IV and V patients was $44.7 \pm 9.7$ years, $48.4 \pm 11.4$ years and $44.0 \pm 13.4$ years respectively. Data analysis revealed that no statistically significant $(p>0.05)$ mean difference in age was found among the three stages of patients. Data indicated that the proportion of male patients were found to be high among the stage V (66.7) compared to stage III (60\%) and stage IV (42.9\%) patients, but the difference was not statistically significant ( $p>0.05)$. Similarly, no statistically significant difference was found among the three groups of patients in terms of their occupation and marital status ( $p>0.05)$. Majority of the patients were married (92.7\%) and the rest were unmarried (7.3\%).

Different types of cardiovascular complications in three stages of CKD are shown in Table 4. 
Table-III

Socio-demographic characteristics of the patients in the three stages of CKD

\begin{tabular}{|c|c|c|c|c|c|c|c|c|c|}
\hline \multirow[t]{3}{*}{ Variables } & \multicolumn{6}{|c|}{ CKD Stages } & \multirow{2}{*}{\multicolumn{2}{|c|}{ Total $(n=109)$}} & $p$ value \\
\hline & \multicolumn{2}{|c|}{$\begin{array}{l}\text { Stage III: } 30- \\
59 \mathrm{ml} / \mathrm{min} \\
(\mathrm{n}=20)\end{array}$} & \multicolumn{2}{|c|}{$\begin{array}{l}\text { Stage IV: 15- } \\
29 \mathrm{ml} / \mathrm{min} \\
(\mathrm{n}=35)\end{array}$} & \multicolumn{2}{|c|}{$\begin{array}{c}\text { Stage V: }<15 \\
\mathrm{ml} / \mathrm{min} \\
(\mathrm{n}=54)\end{array}$} & & & \\
\hline & No. & $\%$ & No. & $\%$ & No. & $\%$ & No. & $\%$ & \\
\hline \multicolumn{10}{|l|}{ Age in years } \\
\hline$<45$ & 10 & 50.0 & 11 & 31.4 & 25 & 46.3 & 46 & 42.2 & \\
\hline 345 & 10 & 50.0 & 24 & 68.6 & 29 & 53.7 & 63 & 57.8 & \\
\hline$*$ Mean \pm SD & \multicolumn{2}{|c|}{$\begin{array}{c}44.7 \pm 9.7 \\
(27-60)\end{array}$} & \multicolumn{2}{|c|}{$\begin{array}{c}48.4 \pm 11.4 \\
(20-65)\end{array}$} & \multicolumn{2}{|c|}{$\begin{array}{c}44.0 \pm 13.4 \\
(18-64)\end{array}$} & \multicolumn{2}{|c|}{$\begin{array}{c}45.5 \pm 12.2 \\
(18-65)\end{array}$} & $0.244^{\mathrm{NS}}$ \\
\hline \multicolumn{10}{|l|}{ Sex } \\
\hline Male & 12 & 60.0 & 15 & 42.9 & 36 & 66.7 & 63 & 57.8 & $0.083^{\mathrm{NS}}$ \\
\hline Female & 8 & 40.0 & 20 & 57.1 & 18 & 33.3 & 46 & 42.2 & \\
\hline \multicolumn{10}{|l|}{ Occupation } \\
\hline Service & 8 & 40.0 & 8 & 22.9 & 22 & 40.7 & 38 & 34.9 & $0.362^{\mathrm{NS}}$ \\
\hline Housewife & 7 & 35.0 & 17 & 48.6 & 16 & 29.6 & 40 & 36.7 & \\
\hline Other & 5 & 25.0 & 10 & 28.6 & 16 & 29.6 & 31 & 28.4 & \\
\hline \multicolumn{10}{|l|}{ Marital status } \\
\hline Married & 19 & 95.0 & 33 & 94.3 & 49 & 90.7 & 101 & 92.7 & $0.745^{\mathrm{NS}}$ \\
\hline Unmarried & 1 & 5.0 & 2 & 5.7 & 5 & 9.3 & 8 & 7.3 & \\
\hline
\end{tabular}

${ }^{*}$ p value reached from one way analysis of variance (ANOVA)

Others p value reached from Chi square test

NS=Not significant $(\mathrm{p}>0.05)$

Table-IV

Relationship between three stages of CKD and different cardiovascular complications

\begin{tabular}{|c|c|c|c|c|c|c|c|}
\hline \multirow[t]{3}{*}{ Variables } & \multicolumn{6}{|c|}{ CKD Stages } & \multirow[t]{3}{*}{$\mathrm{p}$ value } \\
\hline & \multicolumn{2}{|c|}{$\begin{array}{l}\text { Stage III } \\
(n=20)\end{array}$} & \multicolumn{2}{|c|}{$\begin{array}{c}\text { Stage IV } \\
(\mathrm{n}=35)\end{array}$} & \multicolumn{2}{|c|}{$\begin{array}{l}\text { Stage V } \\
(\mathrm{n}=54)\end{array}$} & \\
\hline & No. & $\%$ & No. & $\%$ & No. & $\%$ & \\
\hline \multicolumn{8}{|l|}{$\begin{array}{l}\text { Clinical Cardiac } \\
\text { events }\end{array}$} \\
\hline LVF & 3 & 15.0 & 6 & 17.1 & 22 & 40.7 & $0.018^{\mathrm{S}}$ \\
\hline CCF & 2 & 10.0 & 2 & 5.7 & 5 & 9.3 & 0.789 \\
\hline Angina pectoris & 1 & 5.0 & 4 & 11.4 & 11 & 20.4 & - \\
\hline MI & 0 & .0 & 1 & 2.9 & 4 & 7.4 & - \\
\hline \multicolumn{8}{|l|}{ ECG Findings } \\
\hline $\mathrm{LVH}$ & 3 & 15.0 & 7 & 20.0 & 22 & 40.7 & $0.033^{\mathrm{S}}$ \\
\hline IHD & 4 & 20.0 & 12 & 34.3 & 20 & 37.0 & $0.377^{\mathrm{NS}}$ \\
\hline MI & 0 & .0 & 1 & 2.9 & 4 & 7.4 & - \\
\hline Others & 2 & 10.0 & 5 & 14.3 & 5 & 9.3 & \\
\hline \multicolumn{8}{|l|}{ Echo Findings } \\
\hline $\mathrm{LVH}$ & 3 & 15.0 & 9 & 25.7 & 24 & 44.4 & $0.030^{\mathrm{S}}$ \\
\hline Pericardial effusion & 2 & 10.0 & 6 & 17.1 & 10 & 18.5 & $0.676^{\mathrm{NS}}$ \\
\hline Systolic dysfunction & 1 & 5.0 & 3 & 8.6 & 10 & 18.5 & - \\
\hline Diastolic dysfunction & 2 & 10.0 & 2 & 5.7 & 3 & 5.6 & 0.770 \\
\hline Cardiomyopathy & 1 & 5.0 & 1 & 2.9 & 1 & 1.9 & - \\
\hline \multicolumn{8}{|l|}{ X-ray Findings } \\
\hline Cardiomegally & 4 & 20.0 & 20 & 57.1 & 36 & 66.7 & $0.002^{\mathrm{S}}$ \\
\hline Evidence of heart failure & 3 & 15.0 & 7 & 20.0 & 22 & 40.7 & $0.003^{S}$ \\
\hline
\end{tabular}




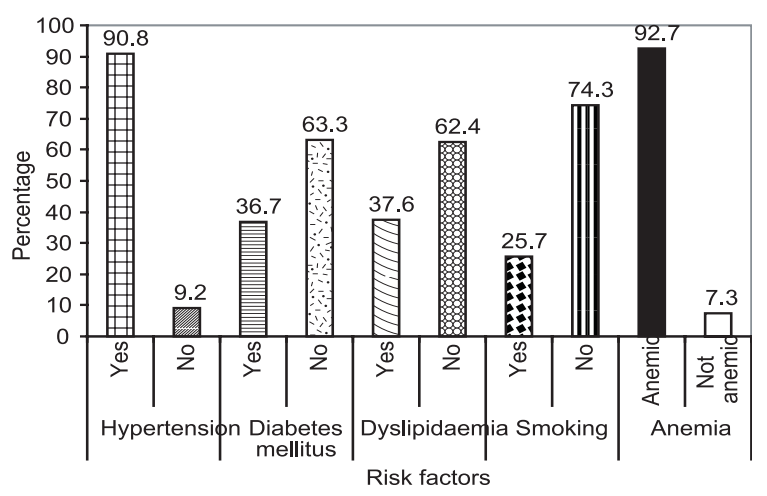

Fig.-2: Percentage distributions of risk factors

It was found that highest percentage of the patients had anemia 101(92.7\%) followed by hypertension 99(90.8\%), dyslipidaemia 41(37.6\%), diabetes mellitus 40(36.7\%), smoking habit 28(25.7\%).

\section{Table-V}

Relationship between cardiovascular complications and risk factors

\begin{tabular}{lccccc}
\hline Risk factors & \multicolumn{6}{c}{ Cardiovascular complications } & p value \\
& \multicolumn{2}{c}{ Yes $(\mathrm{n}=84)$} & \multicolumn{2}{c}{ No $(\mathrm{n}=25)$} & \\
& No. & $\%$ & No. & $\%$ & \\
\hline Hypertension & & & & & \\
Yes & 80 & 95.2 & 19 & 76.0 & $0.003^{\mathrm{S}}$ \\
No & 4 & 4.8 & 6 & 24.0 & \\
Diabetes mellitus & & & & & \\
Yes & 33 & 39.3 & 7 & 28.0 & $0.304^{\mathrm{NS}}$ \\
No & 51 & 60.7 & 18 & 72.0 & \\
Dyslipidaemia & & & & & \\
Yes & 33 & 39.3 & 8 & 32.0 & $0.509^{\mathrm{NS}}$ \\
No & 51 & 60.7 & 17 & 68.0 & \\
Smoking & & & & & \\
Yes & 25 & 29.8 & 3 & 12.0 & $0.074^{\mathrm{NS}}$ \\
No & 59 & 70.2 & 22 & 88.0 & \\
Anemia & & & & & \\
Yes & 81 & 96.4 & 20 & 80.0 & $0.006^{\mathrm{S}}$ \\
No & 3 & 3.6 & 5 & 20.0 & \\
\hline
\end{tabular}

p value reached from Chi square test

Data analysis revealed that the proportion of cardiovascular complications was high among the patients with risk factors. But the data showed statistically significant difference among the patients with hypertension and anaemia $(\mathrm{p}<0.05)$. However, no statistically significant difference was found in terms of diabetes mellitus, dyslipidaemia and smoking ( $\mathrm{p}>0.05)$.

\section{Discussion:}

The present study of cardiovascular complications in patients with Chronic Kidney Disease (CKD) before dialysis has immense clinical as well as public health importance with respect to frequency of cardiovascular complications in the three stages of CKD (Stage III-V) and measures to be taken to prevent them. There is a close relationship between different stages of CKD and CV complications with higher proportion being observed with declining kidney function. Different studies have shown that CV complications are significantly higher in patients with CKD compared to normal population. ${ }^{2}$

So, the present study was undertaken with a view to observe the various cardiovascular complications in patients with chronic kidney disease of stages III-V before dialysis.Our study provides the assessment of the occurrence of cardiovascular complications and of associated risk factors in patients with CKD before dialysis. In our cross-sectional study involving 109 patients of 3 stages of CKD, we observed a significantly high prevalence of $\mathrm{CV}$ complications in patients of stage- $\mathrm{V}$ compared to stages III \& IV in both sexes.

In this study, our main objective was to determine the cardiovascular complications in the three different stages of CKD before dialysis. We used various means for determining different types of $\mathrm{CV}$ events. For diagnosis of heart failure, we relied on clinical history and physical examination and also supplemented by chest $\mathrm{x}$-ray examination. For diagnosis of ischaemic heart disease (IHD) including angina pectoris or myocardial infarction (MI), we took the help of previous history of heart attack needing hospitalization and also electrocardiographic evidence of MI. We used both ECG and echocardiographic criteria for diagnosis of left ventricular hypertrophy (LVH).

In this study it was found that cardiovascular complications were present in all the three stages of CKD but at a significant number in stage $\mathrm{V}$ compared to other two stages. Ischaemic heart disease including angina pectoris or history of myocardial infarction and heart failure were found in the proportion of $19.3 \%$ and $38.8 \%$ respectively. These findings are in consistent with the findings by Levin. ${ }^{35}$ In cohort followed as a part of an observational study, it was found that approximately $30-40 \%$ of all patients seen by nephrologists have a history of IHD. $36,2,26,37$

In this study heart failure was detected in 35\% of patient. The role of impaired kidney function and heart failure prior to dialysis has not been well studied. ${ }^{35}$ In the Canadian multi-centre study, it was found that, those patients who had a change or worsening NYHA (New York Heart Association) class also had anaemia and LVH. An increase in heart failure may simply be due to cardiac decompensation after structural changes. In a recent set of 
studies published by Silverberg ${ }^{28}$ examining the patient with heart failure, benefits were derived from the treatment of haemoglobin value from 10-12 gm/dl. So, early intervention and treatment of risk factors are needed to delay progression of CKD and to prevent development of complications. By radiological examination it was found that cardiomegaly was present at a higher proportion in stage V (66\%) with a statistically significant difference compared to other two stages. The higher percentage of enlarged heart by radiological examination was due to pericardial effusion as well as volume overload. We found pericardial effusion in $17 \%$ of the patients examined. However, echocardiography is the accurate method for detecting LVH.

Left ventricular hypertrophy is an important risk factor for cardiovacular complications in renal disease. Left ventricular hypertrophy is not only a consequence of volume \& pressure overload, but an important independent risk factor. Left ventricular hypertrophy has a high prevalence in ESRD patients, around $75 \%$ of dialysis patients present with $\mathrm{LVH}^{12}$. However, $\mathrm{LVH}$ is also prevalent (25-50\%) in early stages of CKD. ${ }^{13,38}$

Indeed, left ventricular growth itself is a strong, independent predictor of lower survival rates, cardiovascular mortality, arrhythmia and sudden death. ${ }^{39}$ Importantly, left ventricular growth is modifiable through treatment of hypertension and anaemia. ${ }^{40} \mathrm{LVH}$ rose proportionally to GFR decline reaching a value $>50 \%$ in stage V. In the present study, we found LVH in $44.4 \%$ of patients in stage $\mathrm{V}$ by echocardiography and a slightly lower percentage (40.7\%) by ECG. Our study also shows that, LVH increased proportionally from stage III-V with a statistically significant difference.

It is important to emphasize that the prevalence of $\mathrm{CV}$ complications is increased among all patients with CKD, and in those with end-stage renal disease (ESRD). The prevalence of $\mathrm{LVH}$ increases as glomerular filtration declines, and as many as $30 \%$ of patients reaching ESRD already have clinical evidence of ischaemic heart disease or heart failure. ${ }^{9}$ Furthermore, it is important to note that, patients with reduced glomerular filtration rate (GFR) are more likely to die of CVD than they are to develop ESRD. ${ }^{41}$

The limitations of the study included small sample size and study being conducted in a single hospital unit, but the analysis of data have provided with important insights about clinical and public health implications with respect to different types of cardiovascular complications and their associated risk factors in three stages of CKD supported by multivariate analysis.

In conclusion the present cross-sectional study was undertaken in the Department of Nephrology, Bangabandhu Sheikh Mujib Medical University (BSMMU), Dhaka over a period of one year to determine the cardiovascular complications in patients with CKD of stage III-V before dialysis and to observe various risk factors among the CKD patients. There were 109 patients of three stages; stage-III 20(18\%), stage-IV 35(32\%), stage-V 54(50\%), 63 male and 46 female with age from 18 -65 years having a mean age of $45.5 \pm 12$. 2 years.

Data showed that cardiovascular complications were higher in stage- $\mathrm{V}$ with declining renal function and the common cardiovascular manifestations were ischaemic heart disease, LVH, heart failure, pericardial effusion, cardiomegaly and systolic dysfunction. Chronic glomerulonephritis was the commonest cause of CKD (41.3\%) followed by diabetic nephropathy (33.9\%).

Heart failure and left ventricular hypertrophy significantly appeared to be the main cardiovascular complications in CKD stage $\mathrm{V}$ compared to other two stages stage III and $\mathrm{IV})(\mathrm{p}<0.05)$. Anemia, hypertension were identified as important risk factors $(\mathrm{p}<0.05)$.

Since cardiovascular complications begin during the early stages of CKD, it is important to identify patients at risk long before the need for renal replacement therapy arises and to address both the traditional and uraemia-related risk factors. A further study with a large number of study populations is needed with a goal to reducing cardiovascular complications.

\section{Conflict of interest statement none declared}

\section{References:}

1. National Kidney Foundation, K.DOQUI Working Group: The definition, evaluation and classification of chronic kidney disease. Am J Kidney Dis 2002;2 (suppl 1):S46-S75

2. Culleton BF, Larson MG, Wilson PW, et al. Cardiovascular disease and mortality in a community based cohort with mild renal insufficiency. Kidney Int 1999;56(6):2214-9

3. Jungers P, Khoa TN, Massy ZA, et al. Incidence of atherosclerotic arterial occlusive accidents in predialysis and dialysis patients; a muiticentric study in the lle de France district. Nephrol Dial Transplant 1999; 14(4): 898-902

4. National Kidney Foundation (NKF) Kidney Disease Outcome Quality Initiative (K/DOQI) Advisory Board. K/DOQI clinical practice guidelines for chronic kidney disease: evaluation, classification and stratification. Kidney Disease Outcome Quality Initiative. Am J Kidney Dis 2002;39(2 suppl 1): S1-266

5. National Kidney Foundation. DOQI Kidney Disease Outcome Quality Initiative. Am J Kidney Dis 2002;39(suppl.1):S266 
6. Wannamethee SG, Shaper AG, Perry IJ. Serum Creatinine concentration and risk of cardiovascular disease: a possible marker for increased risk of stroke. Stroke 1997;28:557-63

7. Harnett JD, Foley RN, Kent GM, et al. Congestive heart failure in dialysis patients: prevalence, incidence, prognosis and risk factors. Kidney Int. 1995;47:884-90

8. Fink J. Cardiovascular disease and death: Risk factors in the patients with chronic kidney disease. American Society of Renal Week 2003

9. Sarnak, MJ. Cardiovascular complications in chronic kidney disease. Am J Kidney Dis. 2003;41: S11-S17

10. ChertowGm, Normand Sl, Silva LR, et al. Survival after acute myocardial infarction in patients with end-stage renal disease; results from the cooperative cardiovascular project. Am J Kidney Dis 2000; 35(6): 1044-51

11. Renal Data System. USRDS 2003 annual data report: atlas of end-stage renal disease in the United States. Bethesda, Md: National Institute of Diabetes and Digestive and Kidney Diseases renal failure. Lancet 2000;8(356):147-52

12. Foley RN, Parfrey PS, Harnett JD, et al. Clinical and echocardiographic disease in patients starting end-stage renal disease therapy. Kidney Int 1995;47(1):186-92

13. Levin A, Thompson CR, Etheir J, et al. Left ventricular mass index increase in early renal disease: impact of decline in hemoglobin. Am J Kidney Dis 1999;34(1):125-34

14. Jungers P, Massy ZA, Khoa TN, et al. Incidence and risk factors of atherosclerotic cardiovascular accidents in predialysis chronic renal failure patients: a prospective study. Nephrol Dial Transplant 1997;12:2597-602

15. Mailoux LU, Levey AS. Hypertension in chronic renal disease. Am J Kidney Dis 1998;32 (suppl 3): S120-S141

16. Lowe LP, Greenland P, Ruth KJ, et al. Impact of major cardiovascular disease risk factors, particularly in combination, on 22 year mortality in women and men. Arch Intern Med 1998;158: 2007-14

17. Grundy SM, Pasternak R, Greenland P, et al. Assessment of cardiovascular risk by use of multiple risk-factor assessment equation: a statement for healthcare professionals from the American Heart Association and the American College of Cardiology. Circulation 1999;100(13:1481-92

18. Valmadrid Ct, Klein R, Moss Se, et al. The risk of cardiovascular disease mortality associated with microalbuminuria and gross proteinuria in persons with older-onset diabetes mellitus. Arch Intern Med 2000;160(8):1093-100

19. Barkis GL, Willians M, Dworkin K, et al. Preserving renal function in adults with hypertension and diabetes: a consensus approach. National Kidney Foundation Hypertension and Diabetes Committees Working Group. Am J Kidney Dis 2000; 36(3): 646-61.

20. Levey AS, Beto JA, Coronado BE, et al. Controlling the epidemic of cardiovascular disease in chronic renal disease: what do we know/ What do we need to learn? Where do we go from here? National Kidney Foundation Task Force on Cardiovascular Disease. Am J Kidney Dis 1998;32:853-906

21. The Diabetes Control and Complications Trial Research Group. The effect of intensive treatment of diabetes on the development and progression of long-term complications in insulin-dependent diabetes mellitus. N Engl J Med 1993;329(14):977-86

22. UK Prospective Diabetes Study (UKPDS) Group Intensive bloodglucose control with sulphonylureas or insulin compared with conventional treatment and risk of complications in patients with type 2 diabetes (UKPDS 33). UK Prospective Diabetes Study (UKPDS) Group. Lancet 1998; 352(9131):837-53

23. Foley RN, Herzog CA, Collins AJ. Blood pressure and long-term mortality in United States hemodialysis patients: USRDS Waves 3 and 4 Study. Kidney Int 2002;62:1784-90

24. Muntner P, Coresh J, Smith JC, et al. Plasma lipids and risk of developing renal dysfunction: the atherosclerosis risk in communities study. Kidney Int 2000;58(1):293-301

25. Portoles J. The beneficial effects of intervention in early renal disease. Nephrol Dial Transplant 2001;16 Suppl.2:12-5

26. Foley RN, Parfrey PS, Harnett JD, et al. The impact of anaemia on cardiomyopathy, morbidity, and mortality in end-stage renal disease. Am J Kidney Dis 1996;28(1):53-61

27. Holland D, Lam M. Peridictors of hospitalization and death among pre-dialysis patients: a retrospective cohort study. Nephrol Dial Transplant 2000;15(5):650-8

28. Silverberg DS, Wexler D, Blum M, et al. The use of subcutaneous erythropoietin and intravenous iron for the treatment of anaemia of severe, resistant, congestive heart failure improves cardiac and renal failure and functional cardiac class, and markedly reduces hospitalization. J Am CollCardiol 2000;35:1734-1744

29. Orth SR, Ritz E. The renal risk of smoking: an update. CurrOpinNephrolHypertens 2002;11:483-8

30. Stack AG, Bloembergen WE. Prevalence and clinical correlates of coronary artery disease among new dialysis patient in the United States: a cross-sectional study. J Am SocNephrol 2001;12:151623.

31. National Kidney Foundation K/DOQI. Clinical practice guidelines for managing dyslipidaemias in chronic kidney disease 2003.

32. Tonelli M, Moye L, Sacks FM et al. Pravastatin for secondary prevention of cardiovascular events in persons with mild chronic kidney insufficiency. Ann Intrn Med 2003;138:98-104

33. The Seventh Report of the Joint National Committee on prevention, detection, evaluation and treatment of high blood pressure, August 2004

34. American Diabetes Association: Clinical practice, recommendations 2007. Diabetes care 2007; 30 (suppl 1): S1921

35. Parfrey PS, Harnett JD, Griffith SM et al. Congestive heart failure in dialysis patients. Arch Intern Med 1988 Jul;148(17):1519-1525

36. Weiner DE, Tighiouart H, Velagopoulos PT, et al. Effect of anaemia and left ventricular hypertrophy on cardiovascular disease in patients with chronic kidney disease. J Am Soc Nephrol 2005; 16:241-247

37. Kannel WB, Feinleib M, McNamara PM, et al. An investigation of coronary heart disease in families. The F framingham offspring study. Am J Epidemiol 1979;110:281-290

38. Parfrey PS, Foley RN, Harnett JD et al. Outcome and risk factors of ischamic heart disease in chronic uraemia. Kidney Int 1996;49:1428-1434

39. Terkeurs HEDJ, Savage DD, Lester WM et al. New perspective on left ventricular hypertrophy: anatomy, physiology and significance. Clin Cardiol 1989;12:36-49

40. Huting J, Kramar W, Schutterle G et al. Analysis of left ventricular changes associated with chronic haemodialysis. Nephron 1988 ;49:284-90

41. Renger A, Müller M, Jutzler GA, Bette L. Echocardiographic evaluation of left ventricular dimensions and functions in chronic haemodialysis patients with cardiomegaly. Clin Nephrol 1984;21:164-8. 